\title{
Parasocial Interaction, the COVID-19 Quarantine, and Digital Age Media
}

\section{Carol Laurent Jarzyna ${ }^{1}$ (D)}

Received: 20 July 2020 / Revised: 15 October 2020 / Accepted: 27 October 2020 /

Published online:7 November 2020

(c) Springer Nature Switzerland AG 2020

\begin{abstract}
Parasocial interaction, or the one-sided relationships individuals form with characters from television and other media can have negative and positive outcomes. By noting the positive aspects of parasocial interaction and implementing them, individuals can improve their well-being. For instance, while parasocial interaction should not replace real relationships, the behavior can supplement them in filling social needs and decreasing loneliness. Such interaction is helpful for individuals when socialization is not attractive or possible due to a variety of causes. While this type of supplementation has typically been studied in the context of internal shortcomings, it likely also occurs when social deficits are invoked externally, such as through long-term work in remote areas. With the explosion of digital media in the last 25 years, opportunities to augment the fulfillment provided by real relationships with parasocialization have never been so great. Moreover, the recent COVID-19 quarantine greatly restricted real socialization. Those who live alone had e-mail and video calls to sustain them, but virtually no physical contact if they abided quarantine rules. During this time, people appear to have relied on social media and binge-watching streamed series to give themselves a feeling of connection with others more than ever before. The effect of such social surrogacy during the quarantine is only one of many parasocial interaction topics that emerge in the wake of the first wave. This paper will review the relevant digital era literature on parasocial interaction and suggest several areas of exploration into the phenomenon contributed uniquely by the quarantine.
\end{abstract}

Keywords Parasocial interaction $\cdot$ Social media $\cdot$ Well-being $\cdot$ Need to belong . Quarantine $\cdot$ COVID-19

\section{Introduction}

The terms parasocial interaction (PSI) and parasocial relationship (PSR) both refer to the unreciprocated connections that people feel with fictional or media personalities (Horton and Wohl 1956). It is reciprocity, rather than the type of personality with whom the relationship is formed, that is the crucial element determining whether a relationship is real

Carol Laurent Jarzyna

cjarzyna34@gmail.com

1 PsychedUp, Chicago, IL, USA 
or parasocial. Thus, an individual may develop a PSR with various types of personalities. While individuals living in the 1800s likely developed PSRs with protagonists in books, those in the late 1900s did so with television characters. Now social media has allowed for PSRs with reality TV celebrities, Instagram influencers, and the like. While the type of character differs across books, television, or social media, these relationships share that the target generally does not perceive a personal connection to the audience member. There is little or no return of communication or feelings, sometimes because the target is fictional, and at other times because the target has no awareness of the person engaging in PSI.

Despite the one-sided nature of PSI, research has demonstrated that it can have significant effects, both negative and positive, and sometimes go beyond the individual to affect a group of people. The negative impact of PSI includes some untoward effects on real relationships as well as feelings of inferiority when comparing oneself to those they encounter through various forms of media. Groups such as youth, or the people of a particular country, can be affected by PSI through social media too. Some theorists even suspect that PSRs with a reality show celebrity helped the American president get elected (Gabriel et al. 2018). These societal effects are a bit more difficult to categorize as negative or positive and may have elements of both. Despite negative outcomes, research has discovered a host of positive outcomes of PSI as well. PSI and PSRs can help fulfill real social needs in those who take part in it, perhaps even more so for those experiencing social deficits (Jarzyna 2012).

This paper will briefly summarize the history of PSI and review the relevant psychological literature on the topic, emphasizing the most recent, i.e., that of the digital age. While both the negative and positive effects of PSI will be summarized, this paper stresses positive psychological outcomes, with the goal of applying PSI to address individuals' needs. After reviewing the extant PSI literature and determining ways that PSI may be particularly useful during a quarantine, this paper will recommend ideas for future research in the age of digital media, particularly with respect to the unique opportunity the COVID-19 quarantine presents in this domain.

\section{Parasocial Interaction via New Media: in General, and in the Quarantine}

The monumental advances in digitalization made approximately 25 years ago have enabled people to exchange massive amounts of information from around the globe, quickly and easily. Both streamed and social media are societally important outcomes of this. Relevant to examining PSI, changes in television viewing and the advent of social media mean that we consume entertainment, and the celebrities that provide it, much differently than before. Streamed television makes available to us a vast array of programming at any moment, along with the ability to take in a series for extended amounts of time. Additionally, the popular millennial "reality show" genre blurs the line between reality and fiction. This programming features not professional actors but regular people who supposedly appear as themselves. Thus, viewers perceive them as authentic, even though many are aspiring actors, and they rely heavily on scripted scenes. Finally, social media renders it nearly impossible to discern the degree to which an experience is real or fictional. Influencers who are seemingly a friend you met online may get paid to promote a brand and exhibit a certain persona. Filters and beauty apps may even make their physical appearance somewhat fictional, though it is perceived in the moment as real. Real life acquaintances too can 
project identities online that stray substantially from reality. These things taken together indicate an inherent difficulty now, in categorizing a personality as either fictional or real. Given this, perhaps our current means of doing so as researchers is too simplistic. It may be necessary to instead consider a parasocial target on a continuum, which significantly changes how we conceptualize PSI.

Another pivotal way in which digital media necessitates change in thinking about parasocialization lies in the degree of interaction it enables with a personality. The speed of information exchange and the advent of online communities have provided a much greater ability for distant strangers to communicate. Frequently, celebrities, media figures, and influencers now interact online in real time with those who follow them. For much of the history of PSI research though, interaction with a viewer's target was limited to an infrequent response to fan-mail delivered by the postal carrier, or a verbal exchange in a call-in program. Since PSI is partly defined by a lack of communication, the sizeable increase in reciprocation of information, and certainly ideas and emotions, constitute a need for theorists to reevaluate the impact on studying the concept. Just as accounting for various levels of fictionality in parasocial targets may shed new light on PSI, so may accounting for various levels of reciprocity within them. The changes of the recent digital age alone certainly warrant an updated assessment of parasocialization. However, in combination with the recent global quarantine caused by COVID-19, there has perhaps never been greater impetus for expanding parasocial research.

The COVID-19 quarantine presents valuable and unique opportunities for examining PSI, particularly in our now digital age. A few prospects stand out here. These include the fact that the pandemic externally imposed a deficit in socialization across the entire globe, rather than in only certain populations. This is valuable in two ways. Since a weakness in the extant literature is due to a lack of parasocial analysis cross-culturally (Liebers and Schramm 2019), the worldwide nature of the quarantine could benefit this area of research. And while a fertile area of investigation has been how PSI and PSRs can compensate for internal deficits, there is ample reason to explore the phenomenon in externally produced deficits. Related to this, the quarantine added a physical component to social deficits. Never have so many people been restricted from physical contact, with even minimally intimate acts, like shaking hands, being quite risky. Finally, the experience of a modern age pandemic and quarantine abruptly changed many important ways in which we live our everyday lives, not the least of which is how we interact with one another for work and recreational socialization. The very young and old are more at risk for complications, and thus more severe quarantining and its negative social effects. For the average adult, the shift from working predominantly at a workplace to substantially at home has significant implications for psychology, including parasocial interaction. How this widespread behavioral change will affect our inner lives is a domain rife with research potential.

\section{Brief Summary of Relevant Parasocial Research}

Academic inquiry into parasocialization was initially forged by communications theorists. Exploration abutted the psychological realm with the first examinations of the functions that PSI and PSRs commonly serve for people, such as the feeling of companionship they get from watching characters on a soap opera (McQuail 1972). It was not till the 1980s that sustained research into psychological aspects of PSI took root. Factors such as uses (Rubin and Perse 1987), emotion (Rubin et al. 1985), and role in relationships (Rubin and 
McHugh 1987) were investigated. Since this time, psychologists as well as experts in communications and media have researched PSI, pursuing the discipline with usually different, but occasionally overlapping, foci and goals. Because the vast amount of PSI literature accumulated is beyond the scope of this paper, the emphasis here will be the psychological works of the digital age that are applicable to quarantining and related societal changes. Communications research pertinent to that study, however, will not be excluded.

There have been two major reviews of the psychological literature on PSI in the last 20 years (Giles 2002; Liebers and Schramm 2019). At the time of the earlier review, psychological research in the area was young and Giles pointed duly to a need for development of its fundamentals and more exploration in general. Though far from an exhaustive record of the research, the second review draws upon over 250 studies concluded by 2015. An assessment of the reviews, and an analysis of the relatively small amount of psychological literature not included in them, shows a focus in several areas important to the topics of this paper. Those areas include fundamental methodological elements like definitions and measurement, parasocial compensation for social deficits, delineating parallels between parasocial and real relationships, and how PSI functions in specific populations and types of social media.

Both reviews note that a description of the fundamental psychological components and processes of PSI has been evolving for the last few decades. At this stage, it is of great empirical importance to define and operationalize the construct, develop measurement tools, and flesh out methodological issues in general. To this end, some research has focused on accurately defining PSI and PSRs by noting the subtle differences in what they mean and developing parasocial process scales for measurement. One PSI scale created by Schramm and Hartmann (2008) is based on intensity and breadth. Another was created based on characteristics of celebrity targets with appeal beyond exposure through just television (Bocarnea and Brown 2007). However, the scale developed by Rubin et al. (1985) and Rubin and Perse (1987) is clearly the one most often used. For a comprehensive review of PSI/PSR scales, see Liebers and Schramm (2019).

Attention to the targets of PSI is indeed important. Perhaps because identification with parasocial targets is a key psychological element in PSI, Cohen (2006) addressed the need for theoretical development here, particularly for a valid conceptualization of identification, or the degree to which viewers identify with the target in a PSR. Regarding the validity of celebrity conceptualization, theorists have tested this in different categories, such as sports, music, and acting, and developed a scale for measuring celebrity worship (McCutcheon et al. 2002). Important to this paper, PSI with celebrities versus non-celebrities has also been compared (Henry 2011), and much research has contrasted PSRs with fictional versus non-fictional media characters. Almost half of studies conducted as of 2015 examined PSRs with nonfictional characters. Moreover, with newer forms of media, such as social media, that percentage is increasing (Liebers and Schramm 2019). This is not surprising, given that people now commonly form relationships that have parasocial qualities, in online communities like Instagram, Twitter, and Facebook. The results of these studies of PSRs with real characters are important to consider in the research proposed in this paper.

Studies have often compared how the same construct acts in real relationships versus how it acts in relationships that are parasocial. Many of the core components of real relationships have been investigated in PSRs. Commitment and breakup, such significant elements of real relationships, have been much studied in the parasocial realm. Perceptions of infidelity across different types of parasocialization have been examined (Adams 2019) as have feelings of commitment in general (Eyal and Dailey 2012) and toward personalities as different as Oprah Winfrey and Homer Simpson (Branch et al. 2013). 
In real life, we might dwell on the factors involved in our own breakups and analyze the breakups of our friends and acquaintances with almost as much zeal. If a cursory appraisal of the literature on PSI is any indication, we feel similarly about parasocial breakups. Everything from breakups with platonic friends (Eyal and Cohen 2006) to how scandal affects viewers in a parasocial breakup (Hu 2016) has been examined. Theorists have looked at how teens versus adults, and men versus women, respond to parasocial breakups (Cohen 2003). How attachment style and relationship intensity affect parasocial breakups has also been studied (Cohen 2004). Research has examined how viewers feel when a breakup with their favorite characters is caused externally by both a writers' strike (Lather and MoyerGuse 2011) and a primetime series coming to an end (Montes de Oca 2015). In short, researchers appear just as interested in parasocial breakups as the general population is in real breakups, with the studies reviewed here representing only a portion in this realm.

Most major age groups have been analyzed in relation to PSI usage. Children and adolescents are one group that has enjoyed roughly ten percent of the research attention (Liebers and Schramm 2019), perhaps because effects of TV viewing in general is thought to have important effects on kids and teens. Children under 8 years old have been looked at in a study discussing the potential for kids to learn from PSRs with favorite characters (Bond and Calvert 2014). So too, has the nature of parasocial activity in young adolescents been explored (Gleason et al. 2017). Other studies have looked at PSI in children at all ages in between. For an in-depth examination of PSI in this age group, see Calvert and Richards (2014).

The bulk of the literature cited throughout this paper uses a general adult population, with over $40 \%$ using college-aged individuals, likely due to who is available for participation. Thus, there are a great many studies focusing on adults in general. Important to the current paper, and to the aging population in general, research of the last decade has begun to single out older adults' use of PSI. One analysis shows the relation of older adults' use of PSRs to depression (Bernhold 2019; Bernhold and Metzger 2018). Lim and Kim (2011) found that in older viewers, PSI enhanced satisfaction when watching online shopping. Kim and Kim (2017) found positive outcomes for well-being in older people experiencing PSI through travel Web sites. Finally, greater use of PSI has been associated with loneliness in older adults (Chory-Assad and Yanen 2005), perhaps seeking to fill their need for companionship. Still, only about three percent of the amassed research examines PSI in older people. Our aging population, particularly with the constraints put on them by health decline and communicable diseases like COVID-19, may well be a group that could utilize the benefits of PSI. This paper underscores the importance of an expedient research focus on this group.

Finally, with new forms of media created in the digital age, scientists interested in PSI have delved into the construct's role in streamed television and social media. As mentioned previously, this is important because the speed and nature of digital media changes important elements of parasocialization, such as the degree to which personalities are real or fictional, and the degree to which interaction is possible. Streaming of television programs, series, and movies has taken root through digital broadcasting and services such as Netflix, Hulu, and many others. The main result has been an explosion of entertainment offerings on demand, making the target of one's PSR not only available at any time, but repeatable. Binge watching (viewing an entire season of a series in one sitting of many hours) has become popular. Concomitant with these changes has been the overwhelming popularity of reality shows using real people. Adding to the complexity, reality show personalities do not start out as celebrities, and are supposedly appearing as themselves, instead of as actors following a concrete script. This muddles the line between real and fictional characters. 
Online communities like Instagram and Twitter muddle issues of the "realness" of parasocialization targets and degree of personal interaction even more. After all, a "friend" in your online Instagram community might be a celebrity, a regular person who achieved celebrity through that community, or an actual friend or family member. Yet, interaction with people in each of these categories is often largely the same, with famous actors sometimes posting messages and replies to their followers as if they really knew them. Moreover, the pictures you see may be altered by beauty apps, making appearances somewhat fictional. Finally, gaming platforms take the ability for parasocialization a step further with avatar use, motion-sensing technology, and haptic suits that allow for physical sensations.

Though PSI research into new media has not quite kept up with the mushrooming technology itself, it has been increasing and likely accounts for a sharp rise in overall PSI research between 2005 and 2015 (Liebers and Schramm 2019). For example, Henry (2011) compared outcomes of PSI with reality show stars who were famous or not famous before participation in various categories of reality shows. Binge-watching Lorelai and Rory Gilmore, seemingly every girl's best parasocial buddies on Netflix, was also analyzed (Dyche 2017). Parasocial elements experienced with a sports team through the social media site Twitter has been studied (Frederick et. al 2014) as has PSRs with news anchors on Facebook (Farmer 2012). Cross-media extensions such as friending a fictional TV character who has a Facebook account has been shown to increase parasocialization with characters (Kyewski et al. 2018). Likely because social networking sites are used for marketing as well as entertainment, much consumer research has also examined PSI on social networking platforms. Tsiotsou (2015) looked at consumer loyalty as an effect of PSI on various social networking sites (SNS) and celebrity endorsement through SNS was studied by Chung and Cho (2017). In a similar vein, Rasmussen (2018) analyzed the marketing effects of how PSRs with "YouTube beauty celebrities" influenced viewers beliefs. Still, as of 2015, research into new media forms made up less than twenty percent of that in the PSI field. Considering the studies just cited and many similar ones, research into new media has likely continued to rise in the last 5 years, and will continue to do so, based on sharply climbing social media use.

\section{Outcomes of Parasocial Interaction on Individuals and Groups}

Perhaps the most useful takeaway from the literature on PSI regards its outcomes. For what constitutes the worthiness of scientific inquiry if not the potential for it to benefit human life? That being said, research has shown PSI's effects to occur at the individual and group level, in ways that are both positive and negative (and likely neutral at times). Indeed, complexities may render the valence of some outcomes debatable. Regardless, PSI clearly results in either good or bad effects in some scenarios. In looking first to the ill effects of parasocial relationships, they include aggression, the behavior causing problems with real-life relationships, and media addiction and dependency. For instance, those who have PSRs with celebrities sometimes progress to celebrity worship. While some degree of celebrity worship is normal, especially in adolescents, the behavior frequently develops to an unhealthy degree, involving obsessions, compulsions, and elements of addiction (McCutcheon et al. 2002; McCutcheon et al. 2003). Parasocial relationships have been implicated in media addiction and dependency separate from celebrity worship as well (Grant et al. 1991). 
The literature suggests PSI sometimes interferes with real-life relationships. For instance, evidence shows that some forms of PSI, such as "parasocial infidelity" or sexy snapchatting are perceived as legitimate infidelity and cause hurtful feelings in one's romantic relationship (Adam 2019). Additionally, Tukachinsky and Dorros (2018) found that PSRs can be used as a crutch and reinforce unrealistic expectations about relationships, such that young people may be rehearsing scripts through PSI that would not realistically occur.

However, one of the most common negative outcomes that individuals experience from PSI relates to body image and self-esteem. This affects adolescent girls the most and is usually mediated by social comparison. Social comparison is a means of assessing elements for which no objective test exists. Instead, we note how we "measure up" to others like ourselves in the particular regard. Several studies have indicated that in evaluating elements of their own appearance, especially weight, teenage girls frequently experience decreased self-esteem and poorer body image when comparing to a parasocial friend (Eyal and Teleni-Harari 2013; Oxley 2010). In this respect, social media joins a long-standing tradition in print and other media. For decades, psychologists have pointed to a relationship between teens observing unrealistic images of supermodels in magazines and the rise in anorexia. Some experts propose that social media magnifies comparison behavior pertaining to things like wealth, success, and appearance, and especially impacts teens (Social Media and Teen Mental Health 2019). This magnification likely occurs not only because of the substantial increase in exposure created by social media, but also because it allows even regular people to beautify themselves and their surroundings easily and artificially, in a way that is largely imperceptible.

Indeed, findings appear to support that social comparison frequently mediates the relationship between PSI and dissatisfaction, as well as the relationship between general media consumption and dissatisfaction. In this regard, the impact occurs not only at the individual level but at the group level. This is particularly evident when wealth or lifestyle is compared.

Just as beauty has been portrayed unrealistically in various forms of media, so have lifestyle and wealth. For instance, representations of lifestyle on television almost always give an inaccurate idea of the cost of living. It has been noted that the characters who appeared on Friends (Crane and Kauffman 1994-2004) in the 1990s lived in apartments that people of their profession could never have afforded in real life, given the cost of renting real estate in New York City. The same criticism has been made about spending on the series Sex and the City (Star 1998-2004). That is, up-and-coming journalists in the metropolis cannot really afford numerous pairs of thousand-dollar shoes. As common as these elements were in television in the 1990s, they are more so in social media today.

Social influencers often capture in one image a lifestyle of cosmopolitan opulence that is typically attainable only in a picture. For an actual life lived at that standard is obtainable for extremely few. Perusing Instagram, one envisions the lifestyle of, for example, a young flight attendant, to involve pristine surroundings, the ultimate in personal grooming, and consumption of high-end commodities. Yet, these things are not affordable on the salary of a flight attendant. The portrayal of wealthy lifestyles by celebrities, or simply peers who project their lives as better than they truly are, impact people broadly. Viewers of all sorts take in these depictions, compare their own lives to them, and feel short-changed.

Adding to the dilemma, we frequently forget that these depictions are probably embellished. In the pre-social-media era, we at least knew that a barista affording a spacious apartment in the West Village was pure fiction. However, when we see celebrities, our embellished peers, and strangers indulging on Instagram, the representations have varying 
amounts of real and manufactured wealth and lifestyles. We use social comparison to measure ourselves against these norms without attending to or knowing their degree of authenticity. This comparison often results in feelings of relative deprivation. That is, while we as perceivers may not be deprived in the sense that we have enough money for all the essentials of life, like food, health insurance, etc., we are deprived in a relative sense, because it seems that most others like us enjoy so much more. Embellished presentations cause negative emotions because they are realistically unattainable.

And what of true or accurate portrayals of high living standards? After all, standards of living vary greatly across the different nations and social classes we encounter on social media. Authentic presentations of real lifestyles that are unattainable for the viewer result in negative emotions when one's own existence is comparatively meager. In one instance, this social media experience was so extreme and widespread that many believe it was a factor in a major historical event. The Arab Spring arose when large groups of Arab society, particularly young people, became aware of how others like them were living. While resources in their countries were not available in an equitable way, these young people largely did not deem their standard of living unacceptable before their awareness of the inequities. While this awareness had been growing steadily for decades, the Internet made it widespread and thorough, and dissatisfaction culminated with the advent of social media.

El-Meehy (2014) suggested that feelings of relative deprivation led to the Middle Eastern uprising. Relative deprivation can be experienced by an individual or a group and is the subjective feeling that you are not getting what you deserve, especially in light of what others like you are receiving. In relative deprivation, you are not deprived because you do not have your basic needs met, but because you are not getting what you should get in light of what is approved of in your society and what are others have. In describing the beginnings of the uprising, El-Meehy specifically cites Facebook in one instance. Others noted the role of Facebook, YouTube, and Twitter (Eltantawy and Wiest 2011; Farooq et al. 2017) in the historic event. While these theorists implicate social media explicitly for their crucial role in enacting the Arab Spring, they do not speak so explicitly of relative deprivation becoming apparent through PSI in social media. However, in reviewing expert accounts of public sentiment and engagement with social media it clearly looks like a motivator. Salem and Mourtada (2011) come close to implicating PSI through social media. They reference a merging of real-life and social media identities for Arab youth, in their discussion of how these platforms (specifically Facebook, Twitter, and LinkedIn) empowered the young people who formed the backbone of the Arab Spring. The idea that social media and the PSI experienced through it helped spur negative emotions so intense and widespread that they sparked major political change may seem surprising. But as mentioned earlier, research has repeatedly shown that PSI through social media affects trust (Sherman-Morris 2005), political beliefs (Wen and Cui 2014), and voting (De Guzman Centeno 2010).

It is valuable to understand the negative effects of PSI on individuals and groups to help understand feelings that arise while engaging in it and to inform recommendations on behavior. Certainly, we want to avoid engaging in activities that harm us. However, it is also valuable to know the positive outcomes of PSI for the same reasons. If we are aware of benefits to well-being associated with parasocial behaviors, we can use them for our own good and recommend them to others. Social scientists have been prolific in this endeavor.

Much research supports the idea that PSI can at times be used to compensate for internal social deficits, essentially providing real psychological benefits from parasocial behaviors (Derrick et al. 2008; Derrick et al. 2009; Jarzyna 2012). That is not to say that ersatz socialization can completely supplant real socialization in this function, but that it can be a potent supplement. Though not conclusive, some findings have yielded support for this 
concept. For instance, for those who had social challenges such as factors related to cognition (McCutcheon et al. 2003), anxiety (Cole and Leets 1999; Green and Brock 1998; Papachrissi and Rubin 2000), introversion (Weaver 2003), fear of rejection (Derrick et al. 2019), loneliness (Greenwood and Long 2009), or self-esteem (Derrick et al. 2008), engaging in parasocial behaviors significantly aided some measures of well-being. Another study found PSI helpful for those who had experienced trauma, but not for those post traumatic with stress disorder (Gabriel et al. 2017). Even anecdotally, the evidence for parasocial processes aiding well-being seems to be everywhere. One fan of the Hallmark Channel (which enjoys a cult-following) summed it up best in a post commenting on one of the channel's videos: "I really love hallmark channel, [sic] I battle depression and these movies just make me feel so... safe and happy. Thank you." (Maldonado 2020).

More recently, theorists have investigated the potential for parasocial interaction to aid those with developmental disorders, such as Asperger's (Adamo 2004; Ledgin 2011) and have found PSI useful for individuals with Down's syndrome (Whitenack 2015). These studies are just a few of those pertaining to the use of PSI by individuals with social deficits. For a general discussion on how parasocialization affects well-being for those with and without internal deficits, see Hartmann (2016).

Considering the two comprehensive reviews of PSI research and a firsthand look at the last twenty years' literature relevant to this paper, it is clear that research into parasocial processes is worthy of continued study. Research devoted to harnessing PSI's ability to increase well-being, particularly in those with social deficits would be of great benefit to many populations. It is also apparent that new media has so greatly changed our cultural landscape that its function as a platform for PSI cannot be ignored. The COVID-19 quarantine has provided the rare opportunity to look at the intersection of beneficial PSI and social media within a global framework. The next section will discuss specific courses of analysis suggested by the pandemic and resulting quarantine, as well as how PSI might aid our now changed ways of life going forward.

\section{Implications Arising from the COVID-19 Quarantine}

The type of global quarantine we are experiencing has not occurred before in our lifetimes. Thus, the world's reaction, both emotional and behavioral, is unknown. Scientists are just beginning to examine people's basic responses. Our thoughts, feelings, and actions during this digital-age crisis are valuable to informing research about PSI, and in turn, learning more about the outcomes of the construct can advise us on how best to employ it in the future. As stated previously, the quarantine contributes unique elements to studying PSI. Important to cross-cultural research, it provides large populations across the globe who endured long-term social restriction in part by using digital media. This is the very media that we use more and more, and about which we need more research. That includes study into factors like the degree to which today's common target characters are real or fictional, and the extent to which interaction and reciprocity occurs in these relationships. The quarantine externally imposed a social deficit, providing an empirical comparison to the internal deficits often addressed with PSI. It also added a new dimension to social deprivation - the physical one. If social and emotional needs can be partially filled through parasocialization, what about the physical components of those needs, for instance, a hug? This is particularly related to the newest technologies in social media, like the motion and sensation capabilities of haptic suits. Last, 
with the social landscape changed indefinitely, our successes with parasocialization in the past, as well as in the quarantine, can inform coping strategies in a world with social limitations. This may be particularly true for our increasing elderly population, who are more susceptible to COVID-19 complications.

Though it is crucial in this endeavor to know what people were actually doing and feeling during the initial quarantine, the short amount of time since prohibits most scientific assessments of the world's behavioral response to the COVID-19 quarantine. However, we do have some information. Who has not seen news footage of Italy's crooners collaborating on tunes from their balconies (Spary 2020)? So too, have we likely all seen a stuffed animal or two peeping out of a window as part of a toddler quarantine safari (Fortin 2020). Yet, based on federal data, Americans bought more guns in the first month of quarantine than they had in any other month in history, except directly following the election of former President Barack Obama, whom gun rights advocates erroneously thought would greatly restrict gun purchases (Collins and Yaffe-Bellany 2020). Performing some quick data mining, one author reported widespread use of TikTok and Netflix during the initial quarantine, as well as a feeling of fear (Lim 2020). Taken together, these appraisals seem to indicate a somewhat frightened society looking for consolation through parasocial and limited social means. One might see this as the perfect storm for research on PSI.

While most of the research on filling social deficits with parasocial phenomena pertains to those caused internally, there is no reason to suspect that externally caused social deficits, like a quarantine, might be partially filled through PSI as well. Some studies have supported this idea. For instance, participants who experienced social rejection as part of an experiment received positive outcomes from parasocialization (Twenge et al. 2007). In an experiment by Derrick (2012), participants performed a task known to deplete self-control, and regained it through parasocialization. Even more like the social deficit caused by the quarantine are some situations caused by environmental or space research. For instance, experts that study climate change in Antarctica are subject to long periods (six months or more) of relative social deprivation. That is, they are far away from family and friends and interact physically with only a small number of others. Additionally, scientists undertaking preparation to explore Mars anticipated a host of physical and technological challenges, but initially underestimated social challenges.

Because travel to Mars takes roughly 6 months, and communication with Earth involves a 25-min delay, the elite international crew was subject to extreme social isolation in the Mars-500 simulation study. Indeed, a previous study concluded prematurely due to aggression thought to be related to social isolation, including one physical and one borderline sexual assault (Isachenkov 2010). Based on this knowledge, astronauts in the Mars-500 study intentionally packed books, movies, and pictures. Playing movies and video games was scheduled as part of regular activity. These parasocial tools appear to have helped the all-male crew considerably, as the Mars-500 study recorded fewer social/psychological issues and ran to completion 520 days later (Mars-500, Wikipedia).

Take note that the participants in the three studies just discussed were not recruited for internal social deficits, and likely were in the normal range for individual differences like introversion-extraversion, self-esteem, and anxiety. In fact, those in the Mars-500 study were required to have a high degree of physical and mental fitness. These three studies, along with the body of research reviewed earlier, suggest that parasocial interaction could help those with or without internal social deficits during an externally invoked situation of social deprivation, like the COVID-19 quarantine. Thus, social scientists ought to seize the rare opportunity the global quarantine has provided to augment the paucity of crosscultural research on PSI already discussed. 
Since TikTok and Netflix were apparently relied on often during a time of COVID-centered fear and social limitations, how parasocialization functions within these technologies to reduce fear might be evaluated. Alternatively, a study might assess parasocial elements used during the quarantine for their ability to fill other needs. Researchers could survey those quarantined about their use of PSI, as well as their mood and feelings of belonging during the quarantine. Even better, surveying people about their parasocial behaviors, mood, anxiety, and loneliness, during a second wave or second pandemic quarantine could provide even more accurate data, given that self-reports would not have to rely on retrospection. Survey seems an effective and practical method for collecting this data. Indeed, most (64\%) of the studies conducted on parasocialization have utilized it (Liebers and Schramm, 2019).

One last application of the Mars-500 results pertains to the fact that decreased physical contact figured so prominently in it. While internally related deficits may decrease socialization to a large degree, they do not necessarily involve physical deprivation. For instance, even a shy, anxious individual likely interacts with many others, sharing space, talking, and occasionally touching throughout the day. Also, these individuals probably have more intimate contact, like hugging or sitting closely with family and friends than people did during the pandemic lockdown. The physical element of social deprivation has not often been studied in PSI research and is becoming more relevant in a world with quarantines and increased remote work. There are also corresponding technological advances that might factor into this discussion, such as the increasing physical component of virtual interaction, such as AR and technologies like the haptic suit. The concomitant arrival of these technologies with limitations that are at once physical and social begs the question of whether using such technologies as part of parasocialization renders the process more fulfilling. In fact, numerous questions emerge as to how parasocialization might work here. To date, it is not known whether the physical part of socialization can be filled to any degree with parasocial processes.

For this reason, examining the use of haptic suits, which allow one to closely mimic real physical contact, should be studied regarding parasocial elements to which they might lend themselves. Indeed, the full-bodied "Teslasuit" used in AR allows wearers to physically sense elements of the virtual settings, such as objects or characters (Papadopoulos 2020). For as little as 300 USD, people can purchase a haptic suit that enables them to sense touch, motion, temperature, and more. According to one user of this type of technology, the experience of a virtual hug seems almost as good as the real thing (I Can Feel Her Hug Me, 2019), the utility of which cannot be overstated for folks living alone during a long quarantine. Not surprisingly, the technology has been adapted for sexual use (Martindale 2016), enabling parasocialization of a wholly different type. Related to haptic suits, robots are being considered as a tool to fight loneliness in the pandemic. Long used successfully for functional, service purposes, the quarantine has prompted researchers to develop a framework for mitigating loneliness with companion robots (Odekerken-Schröder, Mele, Russo-Spena, Mahr and Ruggiero 2020).

Another technology that integrates AR, avatar use, and haptic suits is that of online video gaming. Society turned to it a great deal during the quarantine (Lim 2020). A population of interest here is younger teens, who comprise only a small portion of participants in the PSI literature. With school being canceled except for shortened online classes, as well as physical contact being all but banned, many boys likely increased their video gaming the most. Yet, in the digital age, video games are played virtually, with both friends and strangers. Motion-sensing devices allow for your actual movements to transpire in the virtual environment. While most gaming experiences do not 
yet utilize haptic suits, it is clearly on the horizon. Recent studies have forayed into the parasocial elements in virtual gaming (Banks and Bowman 2014, 2016; Song and Fox 2015), but more study is warranted due in part to the overwhelming popularity of videogaming in many parts of the globe, particularly with our youth. The initial lockdown and continuing quarantine behaviors provide an ample participant pool for this.

As mentioned in the literature review, older people as well as teens have received only a small percentage of the research focus. This is relevant to the current discussion for a few reasons. The population has aged in the last 20 years, with older individuals now comprising a larger percentage of society in many nations. For these people, COVID-19 is more serious, with higher rates of complications and fatalities. Thus, they need to be most vigilant in protecting themselves through quarantine. However, this vigilance has worn on them.

An activities assistant at a New Jersey residential facility for the elderly stated that after a few months of quarantining in their rooms, residents were frustrated with their severely limited social contact. Despite their distaste for always wearing face masks when socializing, they craved social contact (D. Gabler, personal communication, June $23,2020)$. Others in the long-term care profession echo this account, from residents showing both mental decline and decreased will to live due to the quarantine, comparing it to a prison (Paulin 2020). Indeed, depression rates increase with age and socialization is one agent in combatting that. Both COVID-19 and the loneliness that the quarantine has caused constitute serious risk to the elderly. Experts strongly recommend considering the ill effects of loneliness when developing quarantine guidelines for this population despite their vulnerability to the virus. Specifically, experts advise implementing technology-assisted socialization. In particular, video conferencing of group activities such as religious services and yoga are suggested, as well as general use of social media platforms like Facebook (Conroy et. al 2020). The Campaign to End Loneliness, which emerged in response to the quarantine, encourages seniors to stay connected via apps like Twitter (Coronavirus and Social Isolation 2020). Older people might nurture parasocial and real social relationships by using these apps during quarantine, when the latter is not available, and they do not want to wear a mask or leave their room.

Another parasocial medium for seniors is television programming. The fact that older adults can experience a sense of companionship from PSR with TV characters (Bernhold and Metzger 2018; Eggermont and Vandebosch 2001), coupled with the fact that watching Netflix was a primary quarantine activity certainly, suggests that older people can and did benefit from watching streamed television. It is likely other digital age media might provide benefits too.

The feeling of companionship imparted by PSRs with favorite TV or sports celebrities (Derrick et al. 2008) can also be nurtured when seniors follow their favorite personality on Instagram or Twitter. Many older adults who did not grow up in the social media age still use it, and participate in commercial or public classes on its use. Experts advocating digital technology and social media for the elderly suggest this type of instruction be offered at adult living centers. Again, ersatz socialization should never completely replace real socialization, but it is a needed supplement when the consequences of real socialization are grave. Thus, geriatric populations may not only benefit from engaging in research-advised parasocial processes, they can be studied as to their quarantine behavior and feelings to enrich the same research. 


\section{Conclusion}

Throughout the initial months-long COVID-19 quarantine, as people hoarded toilet paper and bunkered down in their homes, a thought commonly verbalized was that "We live in interesting times." Truly, this is an interesting time. A global pandemic itself has not occurred in over a century. But were it not for sizeable recent technological advances, it would have been a considerably less interesting time. When boredom called, social media answered.

Social media did not just provide us with entertainment, though. It gave us much more than that. Though parasocialization does have noteworthy ill effects, PSI through digital media allowed us to have a sense of togetherness during the quarantine. It is hard to imagine what it would have been like without being able to binge-watch our favorite characters on Netflix, or comment on our favorite influencer's latest ensemble. Research has shown that this type of PSI gives us a feeling of belonging, helps us feel closer to our ideal selves, and raises our self-esteem. These are important things in times of fear.

Social scientists, particularly those who study PSI, should not fail to use the exceptional opportunity the global quarantine provided. It offered large numbers of people utilizing new media for ersatz socialization when confronted with externally imposed social deprivation. Additionally, it did so across the globe. This last fact is important considering the relative lack of cross-cultural studies on parasocialization. As well, the nature of new media has elements that fundamentally challenge the way in which we have traditionally conceived of parasocial interaction. The construct can no longer be conceptualized as depending on characters that are either real or fictional, and interactions that are purely one-sided. Examining the use of new media during the quarantine can help to describe parasocialization at different levels of each component. The quarantine also provides a population exposed to an externally imposed social deficit and with a significant physical aspect. These too, are areas for study. Finally, the pandemic provided more motivation for PSI in those physically vulnerable. Indeed, the severely quarantined elderly might be most in need of parasocialization. By seizing upon the quarantine's utility for answering questions of a social and psychological nature, we will not only learn more about PSI for its own sake, we will be better prepared for any future social restrictions.

Data Availability Not applicable.

Code Availability Not applicable.

\section{References}

Adam, A. (2019). Perceptions of infidelity: A comparison of sexual, emotional, cyber-, and parasocial behaviors. Interpersona: An International Journal on Personal Relationships, 13(2), 237-252. https://doi.org/10.5964/ijpr.v13i2.376

Adamo, S. (2004). An adolescent and his imaginary companions: From quasi-delusional constructs to creative imagination. Journal of Child Psychotherapy, 30(3), 275-295.

Banks, J., \& Bowman, N. D. (2014). Avatars are (sometimes) people too: Linguistic indicators of parasocial and social ties in player-avatar relationships. New Media and Society, 18(7), 1257-1276. https://doi.org/10.1177/1461444814554898 
Banks, J., \& Bowman, N. D. (2016). Emotion, anthropomorphism, realism, control: Validation of a merged metric for player-avatar interaction (PAX). Computers in Human Behavior, 54, 215-223. https://doi.org/10.1016/j.chb.2015.07.030

Bernhold, Q. S. (2019). Parasocial relationships with disliked television characters, depressive symptoms, and loneliness among older adults. Journal of Applied Communication Research, 47(5), 548-570. https://doi.org/10.1080/00909882.2019.1679384

Bernhold, Q. S., \& Metzger, M. (2018). Older adults' parasocial relationships with favorite television characters and depressive symptoms. Health Communication, 35(2), 168-179. https://doi. org/10.1080/10410236.2018.1548336

Bocarnea, M. (2007). Celebrity-persona parasocial interaction scale. Handbook of Research on Electronic Surveys and Measurements, 10, 309-312. https://doi.org/10.4018/978-1-59140-792-8.ch039

Bond, B. J., \& Calvert, S. L. (2014). A model and measure of US parents' perceptions of young children's parasocial relationships. Journal of Children and Media, 8(3), 286-304. https://doi.org/10.1080/17482798. 2014.890948

Branch, S. E., Wilson, K. M., \& Agnew, C. R. (2013). Committed to Oprah, Homer, or House: Using the investment model to understand parasocial relationships. Psychology of Popular Media Culture, 2(2), 96-109. https://doi.org/10.1037/a0030938

Calvert, S., and Richards, M. (2014). Children's Parasocial Relationships. In A. B. Jordan and D. Romer (Eds.), Media and the Well-Being of Children and Adolescents (pp. 187-200). Oxford University Press.

Chory-Assad, R. M., \& Yanen, A. (2005). Hopelessness and loneliness as predictors of older adults' involvement with favorite television performers. Journal of Broadcasting and Electronic Media, 49(2), 182-201. https://doi.org/10.1207/s15506878jobem4902_3

Chung, S., \& Cho, H. (2017). Fostering parasocial relationships with celebrities on social media: Implications for celebrity endorsement. Psychology and Marketing, 34(4), 481-495. https://doi.org/10.1002/ mar. 21001

Cohen, J. (2003). Parasocial breakups: Measuring individual differences in responses to the dissolution of parasocial relationships. Mass Communication and Society, 6(2), 191-202. https://doi.org/10.1207/ s15327825mcs0602_5

Cohen, J. (2004). Parasocial break-up from favorite television characters: The role of attachment styles and relationship intensity. Journal of Social and Personal Relationships, 21(2), 187-202. https://doi. org/10.1177/0265407504041374

Cohen, J. (2006). Audience identification with media characters. In J. Bryant and P. Vorderer (Eds.), Psychology of entertainment (pp. 183-197). Lawrence Erlbaum.

Cole, T., \& Leets, L. (1999). Attachment styles and intimate television viewing: Insecurely forming relationships in a parasocial way. Journal of Social and Personal Relationships, 16(4), 495-511. https://doi. org/10.1177/0265407599164005

Collins, K.\&nbsp; \& Yaffe-Bellany, D. (2020, April 4). About 2 Million Guns Were Sold in the U.S. as Virus Fears Spread. https:/www.nytimes.com/interactive/2020/04/01/business/coronavirus-gun-sales.html

Conroy, K.M., Krishnan, S., Mittelstaedt, S. and Patel, S.S. (2020). "Technological advancements to address elderly loneliness: Practical considerations and community resilience implications for COVID-19 pandemic", Working with Older People, Vol. ahead-of-print No. ahead-of-print. https://nrs.harvard.edu/ URN-3:HUL.INSTREPOS:37364389

Coronavirus and Social Isolation (2020), available at: https://www.campaigntoendloneliness.org/blog/ coronavirus-and-social-isolation (accessed 9 July 2020).

Crane, D. and Kauffman, M. (Producer). (1994-2004).\&nbsp;Friends\&nbsp;[Television series]. Burbank, CA: Warner Bros.

De Guzman Centeno, D. (2010). Celebrification in Philippine Politics: Exploring the relationship between celebrity endorsers' parasociability and the public's voting behavior. Social Science Diliman, 6(1), $66-85$.

Derrick, J. L. (2012). Energized by Television. Social Psychological and Personality Science, 4(3), 299307. https://doi.org/10.1177/1948550612454889

Derrick, J., Gabriel, S., \& Tippin, B. (2008). Parasocial relationships and self-discrepancies: Faux relationships have benefits for low self-esteem individuals. Personal Relationships, 15(2), 261-280. https://doi.org/10.1111/j.1475-6811.2008.00197.x

Derrick, J. L., Gabriel, S., \& Hugenberg, K. (2009). Social surrogacy: How favored television programs provide the experience of belonging. Journal of Experimental Social Psychology, 45(2), 352-362. https://doi.org/10.1016/j.jesp.2008.12.003

Derrick, J. L., Keefer, L. A., \& Troisi, J. D. (2019). Who needs friends? Personality as a predictor of social surrogate use. Personality and Individual Differences, 138, 349-354. https://doi.org/10.1016/j. paid.2018.10.028 
Dyche, C. (2017). Binging on “Gilmore Girls": A Parasocial Exploration of Fans' Viewing Behaviors (Thesis). University of Alabama. https://search.proquest.com/openview/967beed642f597db6d5ce6e2209800f9/ 1 ?pq-origsite $=$ gscholarandcbl=18750anddiss $=y$

Eggermont, S., \& Vandebosch, H. (2001). Television as a substitute: loneliness, need intensity, mobility, life-satisfaction and the elderly television viewer. Communication, 27(2), 10-18. https://doi. org/10.1080/02500160108537902

El-Meehy, A. (2014). Relative Deprivation and Politics in the Arab Uprisings. Social Justice and Development Policy in the Arab World. Issam Fares Institute for Public Policy Working Paper.

Eltantawy, N., \& Wiest, J. (2011). Social media in the egyptian revolution: Reconsidering resource mobilization theory. International Journal of Communication., 5, 1207-1224.

Eyal, K., \& Cohen, J. (2006). When good friends say goodbye: A parasocial breakup study. Journal of Broadcasting and Electronic Media, 50(3), 502-523. https://doi.org/10.1207/s15506878jobem5003_9

Eyal, K., \& Dailey, R. M. (2012). Examining relational maintenance in parasocial relationships. Mass Communication and Society, 15(5), 758-781. https://doi.org/10.1080/15205436.2011.616276

Eyal, K., \& Teleni-Harari, T. (2013). Explaining the relationship between media exposure and early adolescents' body image perceptions: The role of favorite characters. Journal of Media Psychology, 25, 129-141. https://doi.org/10.1027/1864-1105/a000094

Farmer, W. L. (2012). The effect of Facebook on parasocial interaction in local news (thesis). Virginia Polytechnic Institute and State University. https:/vtechworks.lib.vt.edu/bitstream/handle/10919/ 32608/Farmer_WL_T_2012.pdf?sequence=1 andisAllowed=y

Farooq, S., Bukhari, S., \& Ahmed, M. (2017). Arab spring and the theory of relative deprivation. International Journal of Business and Social Science, 8(1), 126-132. https://doi.org/10.30845/ijbss

Frederick, E., Hamrick, M. E., \& Clavio, G. (2014). Bypass and broadcast: Utilizing parasocial interaction to examine @nhl communication on Twitter during the 2012-2013 lockout. Journal of Sports Media, 9(2), 25-44. https://doi.org/10.1353/jsm.2014.0009

Fortin, J. (2020, April 3). Children are hunting teddy bears during the coronavirus outbreak. https://www. nytimes.com/\#publisher. https://www.nytimes.com/2020/04/03/style/teddy-bear-scavenger-hunt.html

Gabriel, S., Read, J. P., Young, A. F., Bachrach, R. L., \& Troisi, J. D. (2017). Social surrogate use in those exposed to trauma: I get by with a little help from my (fictional) friends. Journal of Social and Clinical Psychology, 36(1), 41-63. https://doi.org/10.1521/jscp.2017.36.1.41

Gabriel, S., Paravati, E., Green, M. C., \& Flomsbee, J. (2018). From apprentice to president. Social Psychological and Personality Science, 9(3), 299-307. https://doi.org/10.1177/1948550617722835

Giles, D. C. (2002). Parasocial interaction: A review of the literature and a model for future research. Media Psychology, 4(3), 279-305. https://doi.org/10.1207/s1532785xmep0403_04

Gleason, T. R., Theran, S. A., \& Newberg, E. M. (2017). Parasocial interactions and relationships in early adolescence. Frontiers in Psychology, 8, 255. https://doi.org/10.3389/fpsyg.2017.00255

Grant, A., Guthrie, K., \& Ball-Rokeach, S. (1991). Television shopping: A media system dependency perspective. Communication Research, 18(6), 773-798. https://doi.org/10.1177/009365091018006004

Green, M. C., \& Brock, T. C. (1998). Trust, mood, and outcomes of friendship determine preferences for real versus ersatz social capital. Political Psychology, 19(3), 527-544. https://doi. org/10.1111/0162-895x.00116

Greenwood, D. N., \& Long, C. R. (2009). Psychological predictors of media involvement. Communication Research, 36(5), 637-654. https://doi.org/10.1177/0093650209338906

Hartmann, T. (2016). Parasocial interaction, parasocial relationships, and well-being. In L. Reinecke and M. Oliver (Eds.), The Routledge Handbook of Media Use and Well-Being (pp. 131-144). Routledge.

Horton, D., \& Richard Wohl, R. (1956). Mass communication and para-social interaction. Psychiatry, 19(3), 215-229. https://doi.org/10.1080/00332747.1956.11023049

Henry, N. (2011). Celebrity versus non-celebrity: parasocial relationships with characters in reality-based television programs. (Thesis) https://pdfs.semanticscholar.org/b620/a749468e6caec799cc4fd70095ce142fb9dd.pdf

$\mathrm{Hu}$, M. (2016). The influence of a scandal on parasocial relationship, parasocial interaction, and parasocial breakup. Psychology of Popular Media Culture, 5(3), 217-231. https://doi.org/10.1037/ppm0000068

I Can Feel Her Hug Me With This Haptic VR Suit. (2019, March 26). [Video]. YouTube. https://www. YouTube.com/watch?v=uGeZuFy9PKA

Isachenkov, V. (2010, June 2). Russia launching Mars mission simulation. Msnbc.Com. https://www. nbcnews.com/id/37467140/ns/technology_and_science-space/t/russia-launching-mars-missionsimulation/\#.Xw8p5yhKhPY

Jarzyna, C. (2012, January). Introversion and the Use of Parasocial Interaction to Satisfy Belongingness Needs (Dissertation). Loyola University eCommons. https://ecommons.luc.edu/luc_diss_6mos/6/ 
Kim, I., \& Kim, J. J. (2017). Older adults' parasocial interaction formation process in the context of travel websites: The moderating role of parent-child geographic proximity. Tourism Management, 63, 399_ 416. https://doi.org/10.1016/j.tourman.2017.07.012

Kyewski, E., Szczuka, J. M., \& Krämer, N. C. (2018). The protagonist, my Facebook friend: How crossmedia extensions are changing the concept of parasocial interaction. Psychology of Popular Media Culture, 7(1), 2-17. https://doi.org/10.1037/ppm0000109

Lather, J., \& Moyer-Guse, E. (2011). How do we react when our favorite characters are taken away? An examination of a temporary parasocial breakup. Mass Communication and Society, 14(2), 196-215. https://doi.org/10.1080/15205431003668603

Ledgin, N. (2011). Asperger's and self-esteem: Insight and hope through famous role models (1st ed.). Future Horizons.

Liebers, N., and Schramm, H. (2019). Parasocial interactions and relationships with media characters-An inventory of 60 years of research. Communication Research Trends, 38(2), 1-31. https://www.researchgate. net/publication/333748971

Lim, C. M., \& Kim, Y.-K. (2011). Older consumers' Tv home shopping: Loneliness, parasocial interaction, and perceived convenience. Psychology and Marketing, 28(8), 763-780. https://doi.org/10.1002/ mar.20411

Lim, F. (2020, March 26). Text mining: What are people doing at home during the Coronavirus quarantine? Towards Data Science. https://towardsdatascience.com/text-mining-what-are-people-doing-at-homeduring-the-coronavirus-quarantine-77511172b72e

Maldonado, N. (2020, September 16). Preview + Sneak Peek - Falling for Look Lodge - Hallmark Channel [Comment]. YouTube. https://www.youtube.com/watch?v=D5StMrbKu0o

MARS-500. (2020, June 28). In Wikipedia. https://en.wikipedia.org/wiki/MARS-500

Martindale, J. (2016, April 10). Touch in VR goes in a predictable direction: VR sex suit sells out in hours. Digital Trends. https://www.digitaltrends.com/virtual-reality/tenga-vr-sex-suit/

McCutcheon, L. E., Lange, R., \& Houran, J. (2002). Conceptualization and measurement of celebrity worship. British Journal of Psychology, 93(1), 67-87. https://doi.org/10.1348/000712602162454

McCutcheon, L. E., Ashe, D. D., Houran, J., \& Maltby, J. (2003). A cognitive profile of individuals who tend to worship celebrities. The Journal of Psychology, 137(4), 309-322. https://doi.org/10.1080/ 00223980309600616

McQuail, D., Blumler, J. G., and Brown, J. R. (1972). The television audience: a revised perspective. In D. McQuail (Ed.), Sociology of mass communications: selected readings (pp. 135-165). Penguin.

Montes de Oca, S. (2015, May). Breaking Up Is Hard To Do: An Analysis of Parasocial Relationships and Breakups Among “How I Met Your Mother" Viewers (Thesis). University of Nevada Las Vegas. https://digitalscholarship. unlv.edu/cgi/viewcontent.cgi?article=3393andcontext=thesesdissertations

Odekerken-Schröder, G.,\&nbsp;Mele, C.,\&nbsp;Russo-Spena, T.,\&nbsp;Mahr, D.\&nbsp;and\&nbsp;Ruggiero, A.\&nbsp;(2020), "Mitigating loneliness with companion robots in the COVID-19 pandemic and beyond: an integrative framework and research agenda", Journal of Service Management, Vol. ahead-of-print No. aheadof-print.\&nbsp;https://doi.org/https://doi.org/10.1108/JOSM-05-2020-0148

Oxley, Lindsey (2010) Parasocial comparison: the analysis of a new social comparison target when looking at body satisfaction. Master's Thesis https://udspace.udel.edu/handle/19716/5954 https://doi.org/https://doi.org/ 10.1080/17482798.2018.1463917

Papacharissi, Z., \& Rubin, A. M. (2000). Predictors of Internet use. Journal of Broadcasting and Electronic Media, 44(2), 175-196. https://doi.org/10.1207/s15506878jobem4402_2

Papadopoulos, L. (2020, March 30). This AR/VR Full Body Haptic Suit is a Breakthrough in Human Performance Training. Interestingengineering.Com. https://interestingengineering.com/video/this-ar-vr-fullbody-haptic-suit-is-a-breakthrough-in-human-performance-training

Paulin, E. (2020, September 3). Is extended isolation killing older adults in long-term care? Five months of COVID-19 lockdowns have created a mental health crisis. AARP, https://www.aarp.org/caregiving/ health/info-2020/covid-isolation-killing-nursing-home-residents.html?cmp=SNO-ICM-FB-COVIDCGandfbclid=IwAR0E_zG0hn0ji4iBRtDRBG78GmVZ11dSQ6MdC6BKfud0mlqxWdDYP57WPP0

Rasmussen, L. (2018). Parasocial interaction in the digital age: An Examination of relationship building and the effectiveness of YouTube celebrities. The Journal of Social Media in Society, 7(1), 280-294. https://thejsms. org/tsmri/index.php/TSMRI/article/view/364

Rubin, R. B., \& McHugh, M. P. (1987). Development of parasocial interaction relationships. Journal of Broadcasting and Electronic Media, 31(3), 279-292. https://doi.org/10.1080/08838158709386664

Rubin, A., \& Perse, E. (1987). Audience activity and soap opera involvement. A uses and effects investigation. Human Communication Research, 14(2), 246-268. https://doi.org/10.1111/j.1468-2958.1987. tb00129.x 
Rubin, A., Perse, E., \& Powell, R. (1985). Loneliness, parasocial interaction, and local television news viewing. Human Communication Research, 12(2), 155-180. https://doi.org/10.1111/j.1468-2958.1985. tb00071.x

Salem, F., and Mourtada, R. (2011). Civil movements: The impact of Facebook and Twitter. Arab Social Media Report, 1.

Sherman-Morris, K. (2005). Tornadoes, television, and trust-A closer look at the influence of the local weathercaster during severe weather. Global Environmental Change Part B: Environmental Hazards, 6(4), 201-210. https://doi.org/10.1016/j.hazards.2006.10

Schramm, H., and Hartmann, T. (2008). The PSI-Process Scales. A new measure to assess the intensity and breadth of parasocial processes. Communications: The European Journal of Communication Research, 34(4), 385-401. https://doi.org/https://doi.org/10.5167/uzh-13192

Social media comparison and teen mental health. (2019). https://www.newportacademy.com/resources/ empowering-teens/theory-of-social-comparison

Song, W., \& Fox, J. (2015). Playing for love in a romantic video game: Avatar identification, parasocial relationships, and Chinese women's romantic beliefs. Mass Communication and Society, 19(2), 197-215. https://doi.org/10.1080/15205436.2015.1077972

Spary, S. (2020, March 20). Italians sing together as radio stations unite to broadcast the national anthem. Retrieved October 16, 2020, from https://www.cnn.com/2020/03/20/europe/italian-radio-nationalanthem-intl-scli/index.html

Star, D. (Producer). (1998-2004).\&nbsp;Sex and the City\&nbsp;[Television series]. New York, NY: Warner Bros.

Tsiotsou, R. H. (2015). The role of social and parasocial relationships on social networking sites loyalty. Computers in Human Behavior, 48, 401-414. https://doi.org/10.1016/j.chb.2015.01.064

Tukachinsky, R., \& Dorros, S. (2018). Parasocial romantic relationships, romantic beliefs, and relationship outcomes in USA adolescents: rehearsing love or setting oneself up to fail? Journal of Children and Media, 12(3), 329-345.

Twenge, J. M., Zhang, L., Catanese, K. R., Dolan-Pascoe, B., Lyche, L. F., \& Baumeister, R. F. (2007). Replenishing connectedness: Reminders of social activity reduce aggression after social exclusion. British Journal of Social Psychology, 46(1), 205-224. https://doi.org/10.1348/014466605x90793

Weaver, J. B. (2003). Individual differences in television viewing motives. Personality and Individual Differences, 35(6), 1427-1437. https://doi.org/10.1016/s0191-8869(02)00360-4

Wen, N., \& Cui, D. (2014). Effects of celebrity involvement on young people's political and civic engagement. Chinese Journal of Communication, 7, 409-428. https://doi.org/10.1080/17544750.2014.953964

Whitenack, S. (2015, July). An examination of parasocial relationships in people with Down syndrome (Thesis). University of Cincinnati. https://etd.ohiolink.edu/!etd.send_file?accession=ucin1439308845anddisposition= inline

Publisher's Note Springer Nature remains neutral with regard to jurisdictional claims in published maps and institutional affiliations. 